\title{
Cutaneous Plasmacytoma: A Case Report
}

\author{
Kalaprapa Asavisanu ${ }^{1,{ }^{*}}$, Christos Kasparis ${ }^{1}$ and Ye Lin Hock ${ }^{2}$ \\ ${ }^{1}$ Department of Dermatology, Walsall Manor Hospital, Walsall, England \\ ${ }^{2}$ Department of Histopathology, Walsall Manor Hospital, Walsall, England \\ "Corresponding author: Departments of Dermatology, Walsall Manor Hospital, Walsall, England. Email: kalaprapa@gmail.com
}

Received 2019 December 27; Accepted 2020 January 20.

\begin{abstract}
Introduction: Multiple myeloma is a rare haematological malignancy of plasma cells commonly presenting in the fifth and sixth decade. Uncommonly, multiple myeloma can present with cutaneous manifestations. Usually these lesions occur as a result of an infiltrative extension of osteolytic bone lesions.

Case Presentation: A 72-year-old gentleman with a large malodorous fungating lesion on his right thigh. A skin biopsy demonstrated that the lesions are deposits of known kappa light chain plasma cell myeloma.

Conclusions: Cutaneous plasmacytoma typically presents as erythematous or violaceous hard and tender nodules or plaques. Treatment involves chemotherapy, steroids, local radiotherapy and surgery. The discovery of cutaneous metastatic plasmacytomas can be the first sign of progression of the disease or signal a deteriorating clinical course in multiple myeloma therefore prompt investigation is essential.
\end{abstract}

Keywords: Cutaneous Plasmacytoma, Multiple Myeloma, Skin Disease

\section{Introduction}

Multiple myeloma (MM) is a rare haematological malignancy of plasma cells commonly presenting in the fifth and sixth decade. It involves malignant monoclonal proliferation of plasma cells. This proliferation is usually confined to the bones and the bone marrow.

Uncommonly, multiple myeloma can present with cutaneous manifestations and these occur in $1 \%-5 \%$ of patients $(1,2)$. Usually these lesions occur as a result of an infiltrative extension of osteolytic bone lesions $(3,4)$.

\section{Case Presentation}

A 72-year-old Caucasian gentleman presented with a 6month history of an expanding, malodorous and painful fungating plaque on his right medial thigh.

He had a history of Kappa light chain multiple myeloma that was previously treated with complete remission.

X-ray of the right femur: Rounded lucent areas are seen within the cortex just distal to the prosthesis posteriorly and proximal to the knee in keeping with myelomatous deposits.

Histopathology and immunohistochemistry demonstrated dermal and subcutaneous deposits of monoclonal neoplastic plasma cells showing kappa light chain restriction (clonal population demonstrated) (Figure 1). Positivity for CD138 (Figure 2) and aberrant cyclin D1 positivity supports that these are neoplastic plasma cells.

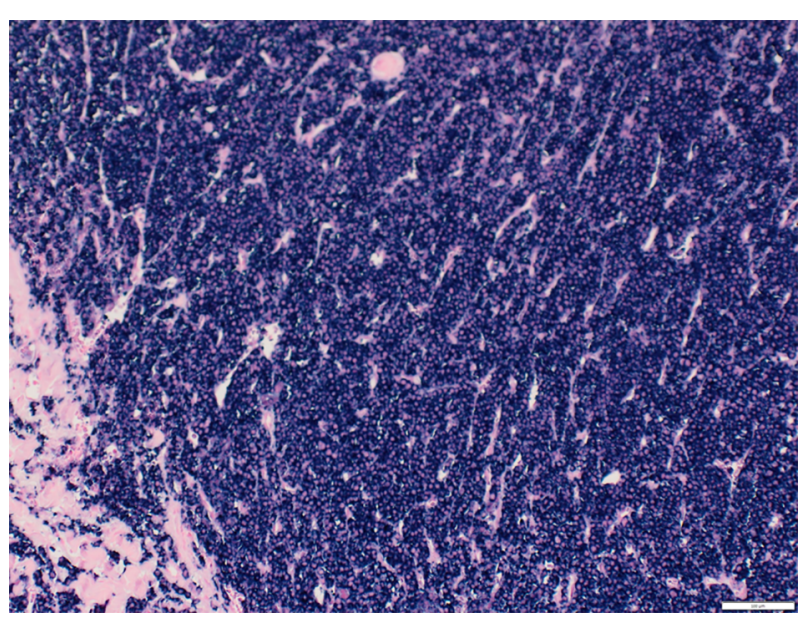

Figure 1. Immunohistochemistry showing kappa light chain restriction in the neoplastic cells

These same neoplastic cells were found to the be in the bone marrow.

Copyright (c) 2020, Journal of Skin and Stem Cell. This is an open-access article distributed under the terms of the Creative Commons Attribution-NonCommercial 4.0 International License (http://creativecommons.org/licenses/by-nc/4.0/) which permits copy and redistribute the material just in noncommercial usages, provided the original work is properly cited. 


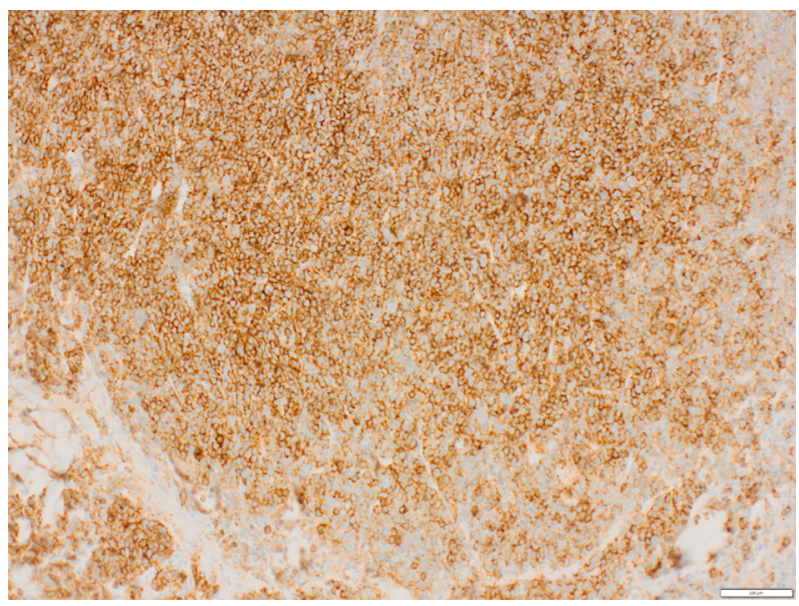

Figure 2. Immunohistochemistry showing CD138 positivity in neoplastic cells

Therefore, the skin and bone marrow findings are entirely consistent with the skin lesions being deposits of known kappa light chain plasma cell myeloma (multiple myeloma).

\section{Discussion}

Typically, plasmacytomas present as erythematous or violaceous hard and tender nodules or plaques with a smooth surface. They may be dermal or subcutaneous or both and can be solitary or multiple. These lesions can occur anywhere in the skin but are most commonly seen in the chest and abdomen (44\%) (5).

Histopathological findings are characterised by monomorphic dermal and subcutaneous infiltrates of plasma cells. Immunohistochemically we see monoclonality of the plasma cells which have strong immunoexpression for CD138 (6).

Cutaneous plasmacytomas tend to occur with MM relapses and in highly aggressive and progressive forms of MM. In both cases the prognosis is poor with an average life expectancy of 12 months post diagnosis with less than $20 \%$ of patients found to be progression free at 5 years (6-9).

Treatment for cutaneous plasmacytoma in multiple myeloma involves chemotherapy, steroids and local radiotherapy. Surgical excision has a role in lesions resistant to radiotherapy or where lesions are very large and symptomatic.

Due to the large size, pain and odour of the lesion in our patient a surgical excision with a wide margin and skin graft repair was elected. He subsequently had chemotherapy with Revlimid and dexamethasone. The lesion resolved completely with no recurrence. Unfortunately de- spite treatment of the skin lesion, his MM progressed and he passed away 4 years later. We believe that our case represents cutaneous plasma cell neoplasm from direct extension of osteolytic lesions (from his right femur) associated with a relapse of his multiple myeloma.

In conclusion, MM can present with cutaneous findings in both primary and recurrent disease. The discovery of cutaneous metastatic plasmacytomas can be the first sign of progression of the disease or signal a deteriorating clinical course in multiple myeloma. Therefore prompt investigations including a skin biopsy are essential in guiding further treatment.

\section{Footnotes}

Authors' Contribution: Kalaprapa Asavisanu drafted and prepared the manuscript and contributed to the analysis and interpretation of the literature. Christos Kasparis was involved in case finding and critical revision of the manuscript for important intellectual content. Ye Lin Hock provided the histopathology images and critical analysis of the histopathology slides.

Conflict of Interests: No conflict of interests declared. Funding/Support: No funding/support.

\section{References}

1. James W, Berger T, Elston D. Andrews' diseases of the skin clinical dermatology. 11th ed. Canada: Elsevier Saunders Publication; 2011.

2. Souza DAFD, Freitas THPD, Paes RAP, Muller H, Hungria VT. Mieloma multiplo com plasmocitomas cutaneos. An Bras Dermatol. 2004;79(5):581-5. doi: 10.1590/s0365-05962004000500009.

3. Requena L, Kutzner H, Palmedo G, Calonje E, Requena C, Perez G, et al. Cutaneous involvement in multiple myeloma: A clinicopathologic, immunohistochemical, and cytogenetic study of 8 cases. Arch Dermatol. 2003;139(4):475-86. doi: 10.1001/archderm.139.4.475. [PubMed: 12707095].

4. Patterson JW, Parsons JM, White RM, Fitzpatrick JE, Kohout-Dutz E. Cutaneous involvement of multiple myeloma and extramedullary plasmacytoma. J Am Acad Dermatol. 1988;19(5):879-90. doi: 10.1016/s01909622(88)70249-2.

5. Jurczyszyn A, Olszewska-Szopa M, Hungria V, Crusoe E, Pika T, Delforge $\mathrm{M}$, et al. Cutaneous involvement in multiple myeloma: A multi-institutional retrospective study of 53 patients. Leuk Lymphoma. 2016;57(9):2071-6. doi: 10.3109/10428194.2015.1128542. [PubMed: 26726867].

6. Santos G, Sousa L, Fernandes T, Joao A. Case for diagnosis. Cutaneous involvement associated to multiple myeloma. An Bras Der matol. 2014;89(1):173-4. doi: 10.1590/abd1806-4841.20142431. [PubMed: 24626671]. [PubMed Central: PMC3938377].

7. Yoo J, Jo M, Kim MS, Jue MS, Park HJ, Choi KH. Cutaneous plasmacytoma: Metastasis of multiple myeloma at the fracture site. Ann Dermatol. 2017;29(4):483-6. doi: 10.5021/ad.2017.29.4.483. [PubMed: 28761299]. [PubMed Central: PMC5500716].

8. Usmani SZ, Heuck C, Mitchell A, Szymonifka J, Nair B, Hoering A, et al. Extramedullary disease portends poor prognosis in multiple myeloma and is over-represented in high-risk disease even 
in the era of novel agents. Haematologica. 2012;97(11):1761-7. doi: 10.3324/haematol.2012.065698. [PubMed: 22689675]. [PubMed Central: PMC3487453].

9. Woo YR, Kim JS, Lim JH, Hwang S, Kim M, Bae JM, et al. Prevalence and clinicopathologic characteristics of multiple myeloma with cutaneous involvement: A case series from Korea. J Am Acad Dermatol. 2018;78(3):471-478 e4. doi: 10.1016/j.jaad.2017.08.054. [PubMed: 29107338]. 